\title{
Knowledge, Attitude \& Practice regarding use of Personal Protective Equipment (PPE) among Dental Assistants Working at Tertiary Care Hospitals of Multan, Pakistan
}

\author{
Mohsin Javaid, Ramesh Kumar, Mudassar Mushtaq Jawad Abbasi, Shoaib Kiyani, Kavita, \\ Saadia Basharat
}

\begin{abstract}
OBJECTIVE: To determine knowledge, attitude, practice of using Personal Protective Equipment (PPE) among dental assistants working at tertiary care hospitals of Multan.

METHODOLOY: Descriptive cross-sectional study was conducted in Multan by completing 98 questionnaires through random sampling technique from private and public sector hospital. Data was analyzed with SPSS, with the significant level being $p<0.05$ by using chia-square test.

RESULTS: Majority 50 (51.02) participants were from private hospitals and $26(52 \%)$ participants from private sector have a good knowledge about the use of PPE where as $34(70.8 \%)$ participants from the public sector had good knowledge as compare to private hospital. $34(68 \%)$ participants from the private sector has a good or positive attitude towards the use of PPE as compared to $36(75 \%)$ participants from the public sector. $29(58 \%)$ participants from the private sector use PPE as compared to $31(65 \%)$ participants from the public sector. P-value for knowledge vs practice of public sector was 0.046 $(p<0.05)$, which was statistically significant and $p$-value for attitude vs practice of public sector was $0.015(p<0.05)$, which was also statistically significant. However, in private sector hospitals we did not find any statistical significance.

CONCLUSION: Study has concluded that the Knowledge, Attitude \& Practice among dental assistants working in Public sector was better than those who were working in private sector hospitals.

KEY WORDS: Dental assistants, Health care workers, Infection Control Guidelines, Personal Protective Equipment and Standard precautions.

This article may be cited as: Javaid M, Kumar R, Abbasi MMJ, Kiyani S, Kavita, Basharat S. Knowledge, Attitude \& Practice regarding use of Personal Protective Equipment (PPE) among Dental Assistants Working at Tertiary Care Hospitals of Multan, Pakistan. J Liaquat Uni Med Health Sci. 2019;18(03):225-30 doi: 10.22442/jlumhs.191830632
\end{abstract}

\section{INTRODUCTION}

Health care Providers specifically are prone to becoming infected by various pathogens if they do not utilize right contamination control measures while giving attention to the patients ${ }^{1}$. Oral health practitioner's are highly at risk as they work with sharp surgical tools with manual dexterity and often with partial access in a situation that is showered in saliva \& sometimes blood. Minimizing the perils of cross-infection is a central aim of every dental procedure, in order to enhance the excellence of attention for patients \& protecting them and to the dental staff; as it is also a legal requirement to promote safety of the patients and doctors as well ${ }^{2}$. Hepatitis B is included in top ten diseases of the world which has serious threats to life ${ }^{3}$ Dental assistants are the health professionals who work closely with patients, under the guidance of a dental surgeon.

Their primarily role is to assist the dental surgeons and are involve in various interventions which includes: Placing and expelling rubber dams, Mechanically polishing the coronal segment of teeth, Whitening the teeth utilizing plate-based frameworks, Preparing and applying pit and fissure sealants, To take initial impressions for examine models ${ }^{4}$. In order to achieve that level of health, caregivers are required to utilize personal protective equipment and abide by all the rules and regulations during medical procedures so that they can avoid chances of getting cross infections. The term personal protective equipment (PPE) is used to key out all protective equipment that a dental professional or dental nurse may utilize in their surgical practice. Typically, this might include the following elements: eyes glasses, facial masks, one time use hand gloves, heavy duty gloves (for cleaning instruments), aprons, and gowns etc ${ }^{2}$. The practice of standard safeguards particularly utilization of PPE is thought to be the best counteractive action procedure against work related transmission of contaminations in human services settings ${ }^{5}$. 
Demand for dental procedures has been heightening in recent era as people have become more cognizant of their oral health and about all the pros good dental aesthetics offers. Maintaining and exercising stringent nonsocial infection control operations therefore have never been so indispensable to ensure the health and protection of oral health care professionals and other subordinating staff who may be circuitously involved in the intervention process. With all of this keeping in mind, it is the responsibility of Dental Health Care Providers to strictly follow the recommended protocols as well as regulations for controlling the contamination, Using PPE which can in turn decrease the chances of propagating of various pathogens and halt the progression of cross infection ${ }^{6}$. Spread of infection may result from polluted instruments or from one person to another via contact ${ }^{7}$.

All the wellbeing work related measures must be known and must be kept by the dental staff. The fundamental significance of cleanliness, the role of equipment used for protection and every one of the obligations and duties associated with should be focused $^{8}$. There was limited published research available to check the KAP among dental assistant in tertiary care hospitals. However this group of dental assistant is usually neglected for the use PPE at their work place that might results in their poor practices. This study has explored the comparison of KAP among dental assistant working in public verses private hospitals of Multan.

\section{METHODOLOGY}

An institution-based cross-sectional study was conducted in tertiary care hospitals of Multan city from April 2018-July 2018. Dental Assistants who had been working for more than one year in these hospitals were included in the study. Outcome variable of this study was personal protective equipment, while the independent variables were age, gender, number of years of experience in dental wards. Sample size was determined by using Open-Epi online calculator with the level of significance of $5 \%$ and confidence interval of $95 \%$. Simple random sampling technique was used in order to get desired sample size. Estimated number of dental assistants in Multan was approximately 250, after doing adjustment by Cochrane correction formula final sample size was calculated as 98. Data was collected by adopting World Health Organization (WHO) structured, self-administered questionnaire with four sectioned questionnaire-based in private \& public sector hospitals of district Multan. A pretesting of tool was done by including 10 dental assistants working in other similar settings, who were not included in this study. Cronbach's alpha (0.8) was used to check the general reliability of tool. Ethical approval was taken from the Institutional Review Board of Health Services Academy Islamabad. After taking the informed consent from the participants, data collection was started. The collected data was analyzed with SPSS, Descriptive statistics were used to explore data and results were generated in percentages, frequencies. Results were displayed in tables, diagrams and graphs, with the significant level being $p<0.05$.

\section{RESULTS}

The percentage of males was $78.6 \%$ (77) while that of females was $21.4 \%$ (21). While considering the marital status, $34.7 \%$ (34) respondents were single, $65.3 \%$ (64) respondents were married. When considering the education level, only 1 was without the formal education, $76.53 \%$ (75) respondents were primary or higher secondary pass, $21.4 \%$ (21) respondents were having a bachelor's degree and only 1 respondent was master's degree holder. Ninety eight percent(49) participants from private sector adopt special precautionary measures while treating Hepatitis B, C, AIDS and potentially infectious patients as compared to $100 \%(48)$ participants from public sector, $32 \%$ (16) participants from private sector have attended the lecture at-least once regarding the awareness of PPE during their job as compared to $54 \%$ (26) participant from public sector. Ninety percent (45) participants from private sector use gloves during the sterilization procedures as compared to $91.6 \%$ (44) participants from public sector who use the gloves during sterilization procedures (Table I).

\section{TABLE I: SOCIODEMOGRAPHIC INFORMATION OF PARTICIPANTS AND SPECIAL PRECAUTIONS ADOPTED BY HEALTH WORKERS}

\begin{tabular}{|l|l|c|c|}
\hline \multicolumn{2}{|l|}{ Variable name with category } & Frequency & Percentage \\
\hline \multirow{3}{*}{ Gender } & Male & 77 & 78.6 \\
\cline { 2 - 4 } & Female & 21 & 21.4 \\
\hline \multirow{3}{*}{ Age } & $16-25$ & 35 & 35.71 \\
\cline { 2 - 4 } & 26 and above & 63 & 64.28 \\
\hline \multirow{4}{*}{$\begin{array}{l}\text { Marital } \\
\text { status }\end{array}$} & Single & 34 & 34.7 \\
\cline { 2 - 4 } & Married & 64 & 65.3 \\
\hline \multirow{5}{*}{ Education } & No formal education & 1 & 1 \\
\cline { 2 - 4 } & $\begin{array}{l}\text { Primary- higher } \\
\text { secondary }\end{array}$ & 75 & 76.53 \\
\cline { 2 - 4 } & Bachelors & 21 & 21.4 \\
\cline { 2 - 4 } & Masters & 1 & 1 \\
\hline
\end{tabular}


Mohsin Javaid, Ramesh Kumar, Mudassar Mushtaq Jawad Abbasi, Shoaib Kiyani, Kavita, Saadia Basharat

\begin{tabular}{|l|c|c|}
\hline \multicolumn{1}{|c|}{ Special precautions adopted for treating in Hospitals } \\
\hline \multicolumn{1}{|c|}{ Variable } & $\begin{array}{c}\text { Private Sector } \\
\text { N (\%) }\end{array}$ & $\begin{array}{c}\text { Public Sector } \\
\text { N (\%) }\end{array}$ \\
\hline $\begin{array}{l}\text { Special precautions for } \\
\text { Hepatitis B, C \& AIDS } \\
\text { patients }\end{array}$ & $49(98)$ & $48(100)$ \\
\hline $\begin{array}{l}\text { Lectures attended } \\
\text { regarding use of PPE }\end{array}$ & $16(32)$ & $26(54)$ \\
\hline $\begin{array}{l}\text { Gloves usage during } \\
\text { sterilization procedures }\end{array}$ & $45(90)$ & $44(91.6)$ \\
\hline
\end{tabular}

Out of 50 participants from the private sector, 41 were male \& 9 were female while out of 48 participants of the public sector, 36 were male \& 12 were female. Ninety six percent(48) participants from private sector use gloves every time while assisting the patient as compared to $100 \%(48)$ participants from public sector. Ninety percent(45) participants from private sector use facemask every time while assisting the patient as compared to $81.25 \%(39)$ participants from public sector. Six percent (3) participants from private sector use protective eyewear every time while assisting the patient as compared to $2.08 \%(1)$ participants from public sector.18\%(9) participants from private sector use head caps every time while assisting the patient as compared to $58.3 \%$ (28) participants from public sector. Four percent (2) participants from private sector use plastic aprons every time while assisting the patient as compared to $2.08 \%$ (1) participants from public sector (Figure I).

\section{FIGURE I: DIFFERENCE IN USE OF PPE BETWEEN PUBLIC AND PRIVATE HOSPITAL}

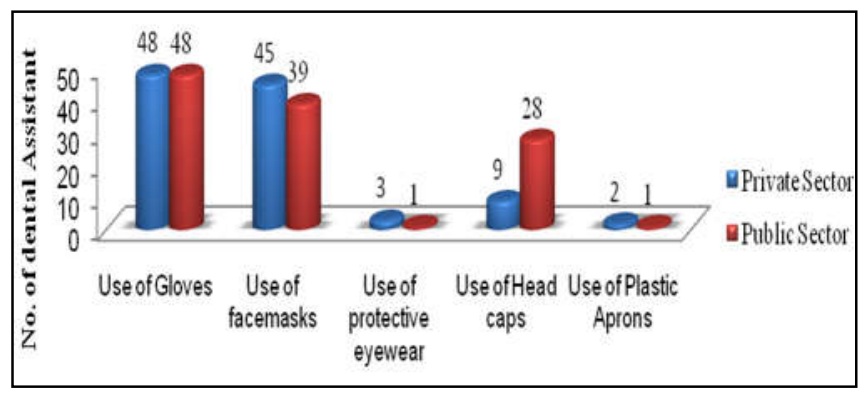

The median value of the cumulative score was taken and found that cumulative score is skewed. The data was divided through median cutoff point because median value is an appropriate measure for the skewed data and published articles also used the median value as a cutoff point.

There are six questions within the domain of knowledge and the lower limit of the score was 6 while the upper value was 10 . The median value of the skewed data was 7 i.e score less than or equal to 7 was considered as good while score more than 7 was

considered as poor.

Twenty six out of $50(52 \%)$ participants from private sector hospitals had a good knowledge about the use of PPE while 24 out of 50 participants $(48 \%)$ had a poor knowledge as compared to 34 out of $48(70.8 \%)$ participants from the public sector who had a good knowledge about the use of PPE \& 14 out of 48 participants $(29.2 \%)$ had a poor knowledge. There were 5 questions within the domain of attitude and the minimum score was 5 while the maximum score was 7. The median score of 5 questions was taken 5 i.e score less than or equal to 5 was considered as good while score more than 5 was considered as poor.

Thirty four out of fifty (68\%) participants from the private sector has a good or positive attitude towards the use of PPE while 16 out of 50 participants (32\%) has a poor or negative attitude towards the use PPE as compared to 36 out of $48(75 \%)$ participants from the public sector who had a good or positive attitude towards the use of PPE \& 12 out of 48 participants (25\%) has a poor or negative attitude towards the use of PPE. There are 6 items within the domain of practice and the minimum score was 11 while the maximum score was 16 . A score of 13 was taken as cutoff point i.e score less than or equal to 13 was considered as good while score more than 13 was considered as poor.29 out of $50(58 \%)$ participants from the private sector use PPE while 21 out of 50 (42\%) participants from the public sector do not use PPE as compared to 31 out of $48(64.6 \%)$ participants from the public sector use PPE while 17 out of 48 (35.4\%) participants from the public sector do not use PPE (Table II).

\section{TABLE II: KAP AMONG THE PARTICIPANTS OF PUBLIC AND PRIVATE HOSPITALS}

\begin{tabular}{|l|l|c|c|}
\hline & Level & Private (\%) & Public (\%) \\
\hline \multirow{3}{*}{ Knowledge } & Good & 52 & 71 \\
\cline { 2 - 4 } & Poor & 48 & 29 \\
\hline \multirow{2}{*}{ Attitude } & Positive & 68 & 75 \\
\cline { 2 - 4 } & Negative & 32 & 25 \\
\hline \multirow{2}{*}{ Practices } & Good & 58 & 65 \\
\cline { 2 - 4 } & Poor & 42 & 35 \\
\hline
\end{tabular}

Knowledge vs attitude and $p$-value for knowledge vs practice for private sector were statistically non-significant. $p$-value for knowledge vs practice of public sector was 0.046 which was statistically significant, $p$-value for attitude vs practice for private sector was statistically non-significant (Table III). 
Personal Protective Equipment (PPE) among Dental Assistants

TABLE III: COMPARISON OF KAP AMONG THE WORKERS IN PRIVATE AND PUBLIC HOSPITAL

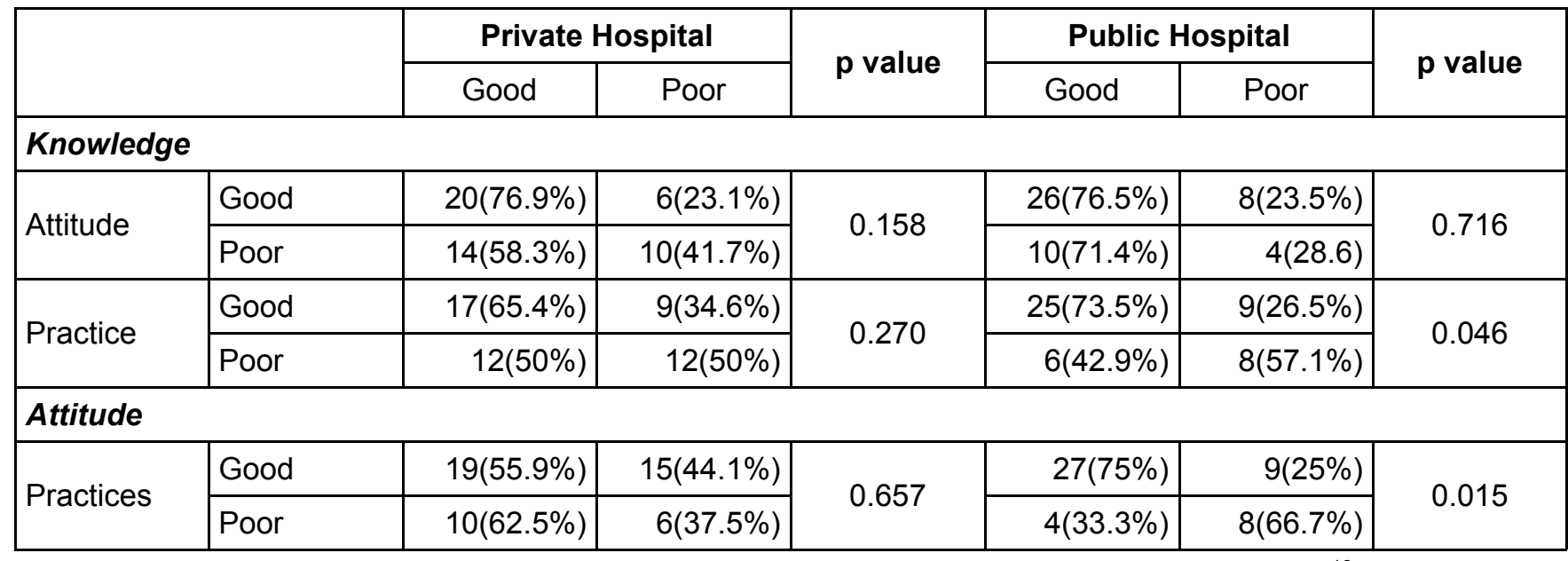

\section{DISCUSSION}

As per Centers for Disease Control and Prevention (CDC) rules worldwide safety measures are set of activities which are essential regarding the avoidance of contamination from blood tolerated or body liquid borne contamination. Universal safety measures are pleasantly outlined and exceptionally successful to control blood borne infections that will secure human services laborers and additionally patients, from getting severe contaminations for example, HBV, HCV, HIV. For that appropriate learning and powerful practices of widespread precautionary measures are exceptionally fundamental ${ }^{9}$.

In our study, $96 \%$ of the participants from private sector said that they use gloves every time while assisting the patient as compared to $100 \%$ participants from public sector who said that they use gloves every time while assisting the patient, results of this study are much better than the findings reported by Burke FJ $1992^{10}$ in U.K (almost half of the participants). In another study, Abushal M $2009^{11}$ found that almost all participants always used gloves, which is almost similar to our findings.

In our study $90 \%$ participants from private sector said that they use facemask every time while assisting the patient as compared to $81.25 \%$ from public sector who reported that they use face mask every time while assisting the patient, these results are much better than the percentage reported by Maqbool A $2016^{12}$ $(46.1 \%)$.

In our study we found that $6 \%$ participants from private sector said that they use protective eyewear every time while assisting the patient as compared to $2.08 \%$ participants from public sector who reported that they use protective eye wear every time while assisting the patient, which is very less than the findings reported by Farrier SL $2006^{13}$, this is due to the reason that there, individual dentist is responsible for the uptake of eye protection for all persons in their surgery environment.

In our study, $18 \%$ of the participants from private sector said that they use head caps every time while assisting the patient as compared to $58.3 \%$ participant from public sector who reported that they use head caps every time while assisting the patient which is less than reported in another study by Al-Essa NA $2017^{14}(65 \%)$.

Four percent of the participants from private sector said that they use plastic aprons every time while assisting the patient as compared to $2.08 \%$ participants from public sector who reported that they use plastic aprons every time while assisting the patient, which is very less than the percentage reported by Maqbool A $2016^{12}(12.7 \%)$. This may be due to unavailability of the aprons. In another study, $\mathrm{Al}$ -Essa NA $2017^{14}$ found that $95 \%$ participants used plastic aprons during patient's treatment, which is much greater than the findings of our study.

In our study Gloves were the most commonly used personal protective equipment (PPE), which is similar to the findings of Arinze-Onyia SU $2018^{15}$.

One third of the participants from private sector have attended the lecture at-least once regarding PPE during their job which is less as compared to half of the participants reported by Amna. While more than half of the participants from public sector have attended the lecture during their job, which is similar to the findings reported by Maqbool A $2016^{12}$ (half of the participants), this may be due to the reason that this public sector institute organizes lectures more often than private sector.

While considering the use of gloves during the sterilization procedures, the results of private \& public 
sector were almost similar i.e $90 \%$ of the participants from private sector reported that they use gloves during the sterilization procedures and $91.6 \%$ of the participants from public sector reported the use of gloves during sterilization procedures. These results of our study are significantly different from those reported in another study by Farrier SL $2006^{13}$ $(<50 \%)$.

P-value for knowledge vs practice of public sector is 0.046 , which is statistically significant and $P$-value for attitude vs practice of public sector is 0.015 , which is also statistically significant. This was similar to the findings reported by Dagher J 2017 ${ }^{16}$, Significant P-value for the public sector may be due to SOP's, policies at governmental level, constant reinforcement, strict monitoring \& evaluation system, adequate basic infection control programs in public sectors and regularly updated recommendations circulated by the government. It might likewise be because of the way that as of late there has been much worry over the disease control works on, including the proceeding with medical instruction session arranged in significance to contamination control rehearses, and strict adherence to the disease control practices ${ }^{17}$.

\section{CONCLUSION}

Knowledge, Attitude \& Practice of both sectors is not as good as in developed countries, and this study concluded that Knowledge, Attitude \& Practice of Public sector is better than the private sector. So institutes should take responsibility to educate their health care workers regarding use of PPE as well as Persistent instructive projects and in addition preparing workshops and the required facilities to allow compliance IC policies must be provided.

Ethical permission: Health Services Academy, Quaid-e-Azam University, Islamabad. Dated:6-4-2018.

Conflict of Interest: There was no any conflict of interest.

Funding: There was no any funding agency.

\section{REFERENCES}

1. Laheij AM, Kistler JO, Belibasakis GN, Välimaa H, de Soet JJ; Eurpoean Oral Microbiology Workshop(EOMW) 2011. Healthcare-associated viral and bacterial infections in dentistry. J Oral Microbiol. 2012; 4(1): 1-10. doi: 10.3402/ jom.v4i0.17659.

2. Hersi M, Stevens A, Quach P, Hamel C, Thavorn K, Garritty C, et al. Effectiveness of Personal Protective Equipment for Healthcare Workers Caring for Patients with Filovirus Disease: A
Rapid Review. PLoS One. 2015. 9;10(10): e0140290. doi: 10.1371/journal.pone.0140290.

3. Patil S, Rao RS, Agarwal A. Awareness and risk perception of hepatitis $B$ infection among auxiliary healthcare workers. J Int Soc Prev Community Dent. 2013; 3(2): 67-71. doi: 10.4103/22310762.122434

4. Taft S, Doston D, Byington LR. Hand function evaluation for dental hygiene students. Can J Dent Hyg 2015; 49 (3): 115-121.

5. Baqir M, Kumar R, Khushk IA, Noorani AA, Ahmed F. Hospital infection control practices among nursing staff working at tertiary care hospital of Khairpur Sindh. J Liaquat Uni Med Health Sci. 2018; 17(2): 117-22. doi: 10.22442/ jlumhs. 181720563.

6. Kumar R, Somrongthong R, Shaikh BT. Knowledge, Attitude and Practices of Health Staff Regarding Infectious Waste Handling at Tertiary Care Health Facilities at Metropolitan City of Pakistan. J Ayub Med Coll, Abbotabad. 2013; 25 (1-2):109-12.

7. Mousa AA, Mahmoud N. Mahmoud, Tag El-Din AM. Knowledge and attitudes of dental patients towards cross-infection control measures in dental practice. Eastern Mediterranean Health J. 1997; 3 (2): 263-73.

8. Györfi A, Fazekas A. Significance of infection control in dentistry. Fogorv Sz 2007;100(4):14152.

9. Solanky $\mathrm{P}$, Baria $\mathrm{H}$, Nerulkar A, Chavda N. Knowledge and practice of universal precautions among nursing staff at a tertiary care hospital in South Gujarat, India. Int J Community Med Public Healh. 2016; 3(9): 2373-6. doi:10.18203/23946040.ijcmph20162890.

10. Burke FJ, Baggett FJ, Wilson NH. Glove wearing by dental surgery assistants in general practice: results of a survey. Dent Update. 1992; 19(6): 263 -5 .

11. Abushal M, Adenubi J. Attitudes of Saudi parents toward separation from their children during dental treatment. Saudi Dent J. 2009; 21: 63-7.

12. Maqbool A, Ronis KA. Assessment of infection control: knowledge and compliance among dental undergraduate students at Nishtar institute of dentistry, Multan. Pakistan J PublicHeal 2016;6 (3):1-6.

13. Farrier SL, Farrier JN, Gilmour AS. Eye safety in operative dentistry - a study in general dental practice. Br Dent J. 2006; 200(4): 218-23.

14. Al-Essa NA, Al-Mutairi MA. To what extent do dental students comply withinfection control practices. Saudi J Dent Res. 2017; 8(1-2): 67-72. 
15. Arinze-Onyia SU, Ndu AC, Aguwa EN, Modebe I, Nwamoh UN. Knowledge and Practice of Standard Precautions by Health-Care Workers in a Tertiary Health Institution in Enugu, Nigeria. Niger J Clin Pract. 2018; 21(2): 149-55. doi: 10.4103/njcp.njcp_69_17.

16. Dagher J, Sfeir C, Abdallah A, Majzoub Z.
Infection Control Measures in Private Dental Clinics in Lebanon. Int J Dent. 2017; 2017: 5057248. doi: $10.1155 / 2017 / 5057248$.

17. Mohiuddin S, Dawani N. Knowledge, attitude and practice of infection control measures among dental practitioners in public setup of Karachi, Pakistan: Cross-sectional survey. J Dow Uni of $\mathrm{H}$ Sci. 2015; 9(1): 3-8.

AUTHOR AFFILIATION:

Dr. Mohsin Javaid

Demonstrator

Multan Medical and Dental College

Multan, Punjab-Pakistan.

Dr. Ramesh Kumar (Corresponding Author)

Assistant Professor

Health Services Academy Islamabad-Pakistan.

Email:drramesh1978@gmail.com

\section{Dr. Mudassar Mushtaq Jawad Abbasi}

Assistant Professor

Health Services Academy Islamabad-Pakistan.

Shoaib Kiyani

Alumni Health Services Academy Islamabad-Pakistan.

\section{Dr. Kavita}

Civil Hospital Mirpurkhas, Sindh-Pakistan.

\section{Saadia Basharat}

Pharmacist

THQ Hospital Gujjar Khan. 